\title{
The direction of pollen flow between two co-occurring rice species, Oryza sativa and 0 . glaberrima*
}

Y. Sano

Two cultivated rice species, Oryza sativa L. and $O$. glaberrima Steud., are often grown mixed in farmers' fields in West Africa. Two sympatric species were collected from two different fields. The frequency of interspecific hybridization between the two species was estimated from the seeds harvested in farmers' fields and in artificial mixtures. The two species were isolated by prezygotic isolating barriers such as autogamy and differences in time of flowering, however, the isolation was incomplete. The frequency of hybridization varied from 0.8 to 4.5 per cent. In addition, all 87 hybrids were found from the seeds which $O$. glaberrima produced. This shows that pollen flow occurs from $O$. sativa to $O$. glaberrima when they hybridize. Generally, $O$. glaberrima had a higher per cent of exserted stigmas as compared with $O$. sativa. The direction of pollen flow appeared to be explained by a higher efficiency of pollen capture in $O$. glaberrima. The genetic consequences were also discussed in relation to gene flow between two distantly related species.

\section{INTRODUCTION}

Introgression across reproductive barriers often occurs between sympatric species or semispecies into another (Anderson and Stebbins, 1954). Isolating barriers are usually much developed between distantly related taxa, reducing the possibility of gene flow between them. However, it has been repeatedly suggested that not only their wild progenitors but also more distantly related taxa have contributed to crop evolution to some extent through introgressive hybridization in maize (Mangelsdorf, 1961; Stalker et al., 1877), wheat (Zohary and Feldman, 1962), sugarcane (Price, 1957) and rice (Chu and Oka, 1970). Although gene transfer was experimentally possible between these crops and their wild relatives, their distinct differences in morphology and the rarity of hybrid swarms make it difficult to establish the genetic contributions of gene transfer under natural conditions.

Oryza glaberrima is endemic in West Africa, while $O$. sativa is of tropical Asian origin. The two cultivated rice species came to be in contact with

\footnotetext{
* This paper is "Genetic studies of speciation in cultivated rice 6". Contribution from National Institute of Genetics, Mishima, Japan, No. 1811.
}

each other after introduction of $O$. sativa into West Africa. At present, the two species are often grown mixed in farmers' fields in West Africa (Oka et al., 1978). Although the interspecific $F_{1}$ hybrid is highly pollen-sterile, it can be experimentally backcrossed with the pollen of either parent (Chu et al., 1978). This suggests a potential for gene flow between them, but this does not imply conclusively that introgression occurs under natural conditions. A basic problem that needs to be solved is whether or not introgression between the two distantly related species has played a role in their adaptation to the growing conditions in West Africa. In order to examine if gene transfer is taking a place between distantly related species such as $O$. sativa and $O$. glaberrima, this paper presents, as the first step, data on the frequency of natural hybridization and the direction of pollen flow.

\section{MATERIALS AND METHODS}

The two cultivated rice species, Oryza sativa and $O$. glaberrima, are isolated from each other by an $\mathrm{F}_{1}$ sterility barriers although their chromosomes $(n=12)$ normally pair in the hybrid (Morinaga and Kuriyama, 1957; Chu et al., 1969). They can 
be distinguished by a few distinct characteristics such as the short, tough ligules and few secondary panicle branches of $O$. glaberrima compared with the long ligules and many secondary panicle branches of $O$. sativa. The strains used were selected from seed samples collected in Nigeria in 1977 (Oka et al., 1978). Strains C8840 (O. sativa) and $\mathrm{C} 8841(O$. glaberrima) had been grown mixed in an upland field (Z-3) and strains C8849 (O. sativa) and $\mathrm{C} 8848$ (O. glaberrima) were from a rainfed lowland site $(\mathrm{KN}-1)$. The relative frequency of $O$. sativa was 48 per cent at Z-3 and 61 per cent at $\mathrm{KN}$-1. At each site, seeds were sampled from seven to ten individuals per species and the bulked seed were used in this study.

The 1:1 mixed-planting experiment was carried out at Mishima. In early May, 18 seedlings of each strain, raised in a greenhouse for four weeks, were transplanted into two boxes $(60 \times 15 \times 15 \mathrm{~cm})$. In each box, the two sympatric strains from each site were planted alternatively at a spacing density of $5 \times 5 \mathrm{~cm}$. The soil was dressed with fertilizers at the rate of 6,5 and $5 \mathrm{~g} \mathrm{~m}^{-2}$ of $\mathrm{N}, \mathrm{P}_{2} \mathrm{O}_{5}$ and $\mathrm{K}_{2} \mathrm{O}$. Seeds were harvested at maturity and the bulked seeds were used for estimating the frequency of $F_{1}$ hybrids under controlled conditions. All the plants were grown in experimentally induced short-day plots ( $c a .12 \mathrm{~h}$ per day).

To look into the differences in floral traits, 14 $O$. sativa and $13 O$. glaberrima strains including the above four strains were grown. The length of spikelet, anther, style and stigma was measured under a microscope. Six or more flowers per strain were examined. The per cent of exserted stigma in bloomed spikelets was determined from more than 100 spikelets per strain. To examine diurnal differences in flowering, flowering time was recorded on a clear day and the observation was repeated more than twice per strain. In total, 1099 spikelets were observed.

\section{RESULTS}

\section{Frequency of interspecific hybridization}

From seed samples collected in two farmers' fields (Z-3 and $\mathrm{KN}-1), 254$ plants in total were grown at Mishima. Out of them, three plants showed complete sterility while all the other plants had high seed sets (53-95 per cent). All the three sterile plants were detected from the seeds collected from $O$. glaberrima plants. The sterile plants had long ligules which characterized $O$. sativa, showing that they were interspecific hybrids between the two species. The frequency of hybrids was 1.6 per cent at $\mathrm{Z}-3$ and 0.8 per cent at $\mathrm{KN}-1$ (table 1). This indicates that the two species naturally hybridize at both sites although the frequency is low (1.2 per cent in total).

When the sympatric strains from each site were mix-planted under controlled conditions, their flowering period partly overlapped although $O$. glaberrima tended to flower earlier than $O$. sativa (table 2). The hybridization frequency in the mixture of two upland strains seemed to be higher than that in the mixture of two lowland strains. The frequency was 4.5 per cent in the mixture of $\mathrm{C} 8840+\mathrm{C} 8841$ and 0.8 per cent in the mixture of C8849+C8848. All 84 hybrids obtained were found from the seeds which $O$. glaberrima produced. This agrees with that found from the seeds collected in farmers' fields, indicating that pollen flow occurs mainly from $O$. sativa to $O$. glaberrima when the two species hybridize.

\section{Differences in floral characteristics}

The direction of pollen flow from $O$. sativa to $O$. glaberrima might be explained by their differences in floral characteristics controlling the efficiency of pollen dispersal and capture. Anther length reflects the amount of pollen grains per anther and

Table 1 Frequencies of natural hybrids between $O$. sativa and $O$. glaberrima observed from the seeds collected in two farmers' fields where the two species coexisted

\begin{tabular}{|c|c|c|c|c|c|}
\hline Site & Species & Strain & $\begin{array}{l}\text { No. of } \\
\text { plants examined }\end{array}$ & $\begin{array}{l}\text { No. of } \\
F_{1} \text { hybrids }\end{array}$ & $\begin{array}{l}\text { Per cent } \\
\text { of hybrids }\end{array}$ \\
\hline \multirow{3}{*}{$\begin{array}{l}\text { Z-3 } \\
\text { (Upland) }\end{array}$} & O. sativa & $\mathrm{C} 8840$ & 67 & 0 & $0 \cdot 0$ \\
\hline & O. glaberrima & C8841 & 62 & 2 & $3 \cdot 2$ \\
\hline & & Total & 129 & 2 & $1 \cdot 6$ \\
\hline \multirow{3}{*}{$\begin{array}{l}\mathrm{KN}-1 \\
\text { (Lowland) }\end{array}$} & O. sativa & C8849 & 57 & 0 & $0 \cdot 0$ \\
\hline & O. glaberrima & C8848 & 68 & 1 & $1 \cdot 5$ \\
\hline & & Total & 125 & 1 & $0 \cdot 8$ \\
\hline
\end{tabular}

Note: The $\mathrm{F}_{1}$ hybrids were identified by long ligules which characterized $O$. sativa in addition to complete sterility. 
Table 2 Frequencies of interspecific $\mathrm{F}_{1}$ hybrids between $O$. sativa and $O$. glaberrima when the two sympatric strains were mix-planted under controlled conditions

\begin{tabular}{|c|c|c|c|c|c|c|}
\hline Site & Species & Strain & $\begin{array}{l}\text { Flowering } \\
\text { period }\end{array}$ & $\begin{array}{l}\text { No. of } \\
\text { plants examined }\end{array}$ & $\begin{array}{l}\text { No. of } \\
F_{1} \text { hybrids }\end{array}$ & $\begin{array}{l}\text { Per cent of } \\
\text { hybrids }\end{array}$ \\
\hline \multirow{3}{*}{$\begin{array}{l}\text { Z-3 } \\
\text { (Upland) }\end{array}$} & O. sativa & $\mathrm{C} 8840$ & July 24-Aug. 9 & 791 & 0 & $0 \cdot 0$ \\
\hline & O. glaberrima & $\mathrm{C} 8841$ & July 19-July 29 & 798 & 71 & $8 \cdot 9$ \\
\hline & & Total & & 1589 & 71 & $4 \cdot 5$ \\
\hline \multirow{3}{*}{$\begin{array}{l}\text { KN-1 } \\
\text { (Lowland) }\end{array}$} & O. sativa & C8849 & July 27-Aug. 14 & 795 & 0 & $0 \cdot 0$ \\
\hline & O. glaberrima & C8848 & July 22-Aug. 3 & 786 & 13 & $1 \cdot 7$ \\
\hline & & Total & & 1581 & 13 & $0 \cdot 8$ \\
\hline
\end{tabular}

Note: The $F_{1}$ hybrids were identified by long ligules which characterized $O$. sativa in addition to complete sterility.

length of style and stigma are associated with the ability of pollen capture. However, table 3 shows no significant difference in length of anther, style and stigma between the sympatric strains from Z-3. In the sympatric strains from $\mathrm{KN}-1, O$. glaberrima had a longer styles and shorter stigmas than $O$. sativa. On the other hand, the degree of exserted stigma greatly differed between the two species. $O$. glaberrima had a high per cent of exserted stigma than $O$. sativa. This difference implies that $O$. glaberrima is more efficient for pollen capture, which is consistent with the direction of pollen flow observed. Even when their flowering period overlap, they cannot interbreed unless they flower at the same time in a day. Although $O$. glaberrima tended to flower earlier than $O$. sativa, isolation due to the diurnal difference was also incomplete (table 3).

As to the floral differences, 27 strains of the two species which were from West Africa were compared under controlled conditions (table 4). Generally, O. glaberrima tended to have a higher per cent of exserted stigmas and shorter spikelets than $O$. sativa. No significant difference was detected in length of anther, style and stigma between the two species. In addition, although $O$. glaberrima tended to flower earlier than $O$. sativa, isolation due to the diurnal difference was also incomplete (fig. 1) as found in the sympatric strains.

\section{DISCUSSION}

Oryza sativa was introduced into West Africa mainly after the 15th century. After introduction, $O$. sativa spread across the West African rice zone where $O$. glaberrima was well established (Porteres, 1950). The two rice species are often grown mixed at present in farmers" fields and natural interspecific hybrids occasionally occur in the fields (Oka et al., 1978). Introgression between them has been assumed to occur from field observations (Borgel and Second, 1978; Steele, 1978 ) but has never been conclusively demonstrated. Usually, farmers use a part of their harvest

Table 3 Means and their standard deviations in parentheses for floral characteristics of sympatric strains of $O$. sativa and $O$. glaberrima collected from upland and lowland fields

\begin{tabular}{|c|c|c|c|c|c|c|c|c|}
\hline \multirow[b]{2}{*}{ Site } & \multirow[b]{2}{*}{ Species } & \multirow[b]{2}{*}{ Strain } & \multicolumn{4}{|c|}{ Length in $\mathrm{mm}$} & \multirow{2}{*}{$\begin{array}{l}\text { Per cent of } \\
\text { exserted stigma }\end{array}$} & \multirow{2}{*}{$\begin{array}{l}\text { Flowering } \\
\text { time }\end{array}$} \\
\hline & & & Spikelet & Anther & Style & Stigma & & \\
\hline \multirow[t]{3}{*}{$\begin{array}{l}\text { Z-3 } \\
\text { (Upland) }\end{array}$} & O. sativa & $\mathrm{C} 8840$ & $\begin{array}{l}8 \cdot 5 \\
(0 \cdot 3)\end{array}$ & $\begin{array}{l}1 \cdot 70 \\
(0 \cdot 14)\end{array}$ & $\begin{array}{c}2 \cdot 10 \\
(0 \cdot 22)\end{array}$ & $\begin{array}{c}0.66 \\
(0.04)\end{array}$ & $23 \cdot 9$ & $\begin{array}{l}\text { am 11:08 } \\
(18 \mathrm{~min})\end{array}$ \\
\hline & O. glaberrima & C8841 & $\begin{array}{c}7 \cdot 6 \\
(0 \cdot 2)\end{array}$ & $\begin{array}{l}1.68 \\
(0.05)\end{array}$ & $\begin{array}{c}2 \cdot 33 \\
(0 \cdot 13)\end{array}$ & $\begin{array}{c}0.74 \\
(0.12)\end{array}$ & $53 \cdot 5$ & $\begin{array}{l}\text { am } 10: 28 \\
(29 \mathrm{~min})\end{array}$ \\
\hline & & $t$ value & $6 \cdot 114^{* *}$ & 0.329 & $2 \cdot 203$ & $1 \cdot 549$ & - & $2 \cdot 856^{*}$ \\
\hline \multirow[t]{3}{*}{$\begin{array}{l}\text { KN-1 } \\
\text { (Lowland) }\end{array}$} & O. sativa & C 8849 & $\begin{array}{c}8.5 \\
(0.4)\end{array}$ & $\begin{array}{c}1 \cdot 83 \\
(0 \cdot 10)\end{array}$ & $\begin{array}{c}1 \cdot 88 \\
(0.21)\end{array}$ & $\begin{array}{c}1 \cdot 10 \\
(0 \cdot 16)\end{array}$ & $18 \cdot 9$ & $\begin{array}{l}\text { am } 10: 18 \\
(46 \mathrm{~min})\end{array}$ \\
\hline & O. glaberrima & C 8848 & $\begin{array}{c}7.7 \\
(0.5)\end{array}$ & $\begin{array}{c}1.88 \\
(0 \cdot 12)\end{array}$ & $\begin{array}{c}2 \cdot 13 \\
(0 \cdot 17)\end{array}$ & $\begin{array}{c}0.88 \\
(0.11)\end{array}$ & $65 \cdot 9$ & $\begin{array}{l}\text { am 9:36 } \\
(18 \mathrm{~min})\end{array}$ \\
\hline & & $t$ value & $3 \cdot 060^{*}$ & 0.784 & $2 \cdot 236^{*}$ & $2 \cdot 772^{*}$ & - & $2 \cdot 075$ \\
\hline
\end{tabular}

\footnotetext{
*, ** show significant at 5 per cent and 1 per cent, respectively.
} 
Table 4 Differences in floral characteristics between $O$. sativa and $O$. glaberrima collected in West Africa

\begin{tabular}{|c|c|c|c|}
\hline \multirow[b]{2}{*}{ Trait } & \multicolumn{2}{|l|}{ Species } & \multirow[b]{2}{*}{$\begin{array}{l}t \text { value } \\
(\mathrm{df}=25)\end{array}$} \\
\hline & $\begin{array}{l}\text { O. sativa, } N=14 \\
\text { (s.d.) }\end{array}$ & $\begin{array}{l}\text { O. glaberrima, } N=13 \\
\text { (s.d.) }\end{array}$ & \\
\hline $\begin{array}{l}\text { Spikelet } \\
\text { length, } \mathrm{mm}\end{array}$ & $\begin{array}{c}8 \cdot 2 \\
(0 \cdot 8)\end{array}$ & $\begin{array}{c}7 \cdot 3 \\
(0 \cdot 4)\end{array}$ & $3 \cdot 466^{* *}$ \\
\hline Anther & 1.88 & $1 \cdot 71$ & $1 \cdot 803$ \\
\hline length, mm & $(0 \cdot 29)$ & $(0 \cdot 20)$ & \\
\hline Style & 0.51 & 0.50 & 0.629 \\
\hline length, $\mathrm{mm}$ & $(0 \cdot 10)$ & $(0.04)$ & \\
\hline Stigma & 1.03 & 0.98 & 0.650 \\
\hline length, $\mathrm{mm}$ & $(0 \cdot 25)$ & $(0 \cdot 20)$ & \\
\hline Exserted & $18 \cdot 4$ & $57 \cdot 2$ & $8 \cdot 600^{* *}$ \\
\hline stigma, $\% \dagger$ & $(11 \cdot 9)$ & $(10 \cdot 3)$ & \\
\hline Flowering & am $10: 57$ & am $9: 46$ & $6 \cdot 508 * *$ \\
\hline time & $(31 \mathrm{~min})$ & $(24 \mathrm{~min})$ & \\
\hline
\end{tabular}

** Shows significant at 1 per cent.

$\dagger$ Shows that data were transformed into Arcsin $\sqrt{ }$ per cent before $t$ test.

as the seed for the next season. The two species are randomly direct-seeded such that they are forced to coexist in farmers' field (Sano et al., 1984). The present result indicates that isolation due to differences in flowering time is generally incomplete between the two species and they interbreed at a low frequency under natural conditions.

The two cultivated rice species are predominantly self-pollinated species. Autogamy prevents gene flow from other plants and acts as a mechanism of isolation. In wild rice species $(O$. rufipogon and $O$. longistaminata), Oka and Morishima (1967) estimated 20 to 100 per cent outcrossing and they observed that the level of outcrossing is associated with the timing of pollen

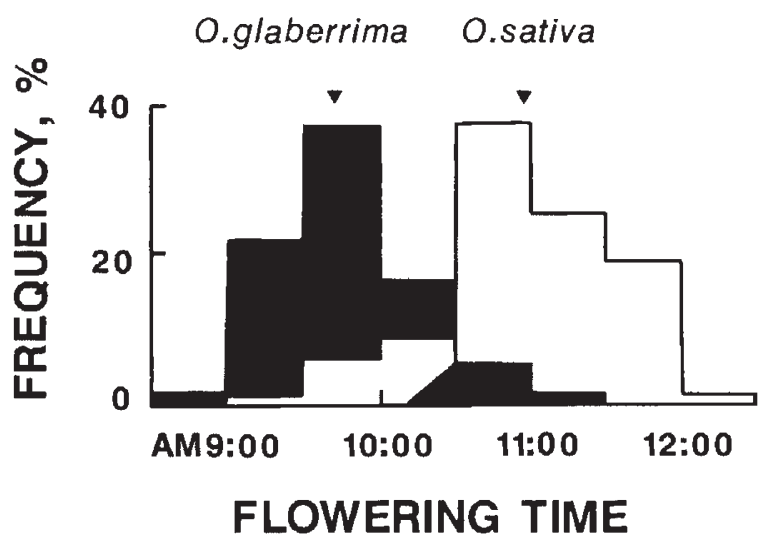

Figure 1 Diurnal difference in flowering time between $O$. sativa (14 strains, 467 spikelets) and $O$. glaberrima (13 strains, 632 spikelets). emission, pollen production and lengths of style and stigma although there was no significant difference in pollen size among wild and cultivated species. The two cultivated rice species shed pollen on their stigma 1-3 min after flowering, so they have a high selfing rate under natural conditions (Oka and Morishima, 1967; Virmani and Athwal, 1973). A conspicuous feature of this study is the direction of pollen flow from $O$. sativa to $O$. glaberrima. In wind-pollinated species, the pollen scatters at random in contrast to the specificity often found between plants and pollinators. Effective wind-pollination is affected by various factors including pollen production, anther and stigma exposed, size of pollen and stigma, density and shape of the plant, surrounding vegetation and distance (Levin and Kerster, 1974; Whitehead, 1969).

The present study showed that $O$. glaberrima tends to have a high per cent of exserted stigma and shorter spikelets than $O$. sativa, indicating that $O$. glaberrima has a high ability to capture pollen compared to $O$. sativa. The spikelet seems to act as an obstacle for pollen capture in $O$. sativa. Hence, the direction of pollen flow appears to result from the different efficiency for pollen capture although both species are predominantly selfpollinated species in nature. In this study, no interspecific hybrid was found from the seeds harvested from $O$. sativa. This cannot be explained only by the difference in the per cent of exserted stigma since $O$. sativa also have some stigma exposed. Additional mechanisms such as efficient pollen transport, cross incompatibility and pollen competition must be involved. Whatever the mechanisms 
involved are, pollen flow occurs mainly from $O$. sativa to $O$. glaberrima when they hybridize.

As mentioned before, although the $F_{1}$ hybrids are completely pollen-sterile, backcrossing is possible as the female parent since 20-30 per cent embryosacs remain functional (Chu et al., 1969). Fertility is recovered quickly by backcrosses and $\mathrm{BC}_{1} \mathrm{~F}_{1}$ and $\mathrm{BC}_{2} \mathrm{~F}_{1}$ produce selfed progenies (Sano et al., 1980). Further, the $F_{1}$ plants have larger stigmas than the parents suggesting a high ability of pollen capture (unpublished). Some genes were experimentally transfered between the two species by backcrossing (Yabuno, 1977) but a recombination restriction and the rapid recovery of parental phenotypes occurred in the hybrid derivatives (Sano et al., 1980). The recovery of parental types might result from the $\mathrm{M}-\mathrm{V}$ linkage as discussed by Grant (1981). As a consequence, they can coexist without losing their identity even after hybridization. This might make it difficult to detect hybrid derivatives or intermediate types under natural conditions even though they hybridize. However, this does not imply that any gene transfer is impossible between them after hybridization.

If the hybrid was backcrossed to the parental species, both $O$. sativa and $O$. glaberrima types would be expected in later generations. In such a case, it is also expected that the derivatives of $O$. sativa type would have the cytoplasm of $O$. glaberrima in addition to the $O$. sativa like nucleus since the maternal parent of the $F_{1}$ hybrid is likely to be $O$. glaberrima as found in the present study. It should be noted that, if pollen flow took a place from $O$. sativa to $O$. glaberrima, cytoplasmic gene flow would occur in the reverse direction.

The cytoplasm of Asian strains of $O$. sativa is different from that of $O$. glaberrima (Yabuno, 1977; Sano, 1985). Thus, the combination of the nucleus of $O$. glaberrima with the cytoplasm of Asian strains of $O$. sativa always shows cytoplasmic male sterility. However, the combination of $O$. glaberrima cytoplasm and $O$. sativa nucleus, which is expected from the direction of pollen flow, has no adverse effect on fertility. Theoretically, Takahata and Slatkin (1984) revealed that when two species hybridize it is difficult to prevent the introgression of extranuclear genomes unless there is any adverse effect from nucleo-cytoplasmic incompatibility. In other words, cytoplasmic genes could be transferred rather frequently as compared with nuclear genes which produce various abnormalities in the hybrid derivatives between the two species. Further investigations on cytoplasmic gene flow from $O$. glaberrima to $O$. sativa might offer a clear evidence of introgression between the two rice species in West Africa.

\section{REFERENCES}

ANDERSON, E. AND STEBBINS, G. L. 1954. Hybridization as an evolutionary stimulus. Evolution, 8, 378-388.

BORGEL, A. AND SECOND, G. 1978. Prospection des varietes traditioelles et des especes sauvages de riz au Tchad et Cameroun. Rapport de Mission: 19 Octorbre-23 Decembre 1977. ORSTOM, Centre d'Adiopodoume, Cote d'Ivoire, p. 1-17.

CHU, Y. E., MORISHIMA, H. AND OKA, H. I. 1969. Reproductive barriers distributed in cultivated rice species and their wild relatives. Jpn. J. Genet., 44, 207-223.

CHU, Y. E. AND OKA, H. I. 1970. Introgression across isolating barriers in wild and cultivated Oryza species. Evolution, 24, 344-355.

GRANT, v. 1981. Plant speciation. Columbia Univ. Press, New York.

LEVIN, D. A. AND Kerster, H. W. 1974. Gene flow in seed plants. Evol. Biol., 7; 139-220.

MANGELSDORF, P. C. 1961. Introgression in maize. Euphytica, 10, 157-169.

MORINAGA, T. AND KURIYAMA, H. 1957. Cytological studies on Oryza sativa L. IX. The $\mathrm{F}_{1}$ hybrids of $O$. sativa and $O$. glaberrima Steud. Jpn. J. Breed., 7, 57-65.

OKA, H. I. AND MORISHIMA, H. 1967. Variations in the breeding systems of a wild rice, Oryza perennis. Evolution, 21, 249258.

OKA, H. I., MORISHIMA, H., SANO, Y. AND KOIZUMI, T. 1978. Observations of rice species and accompanying savanna plants on the southern fringe of Sahara desert. National Institute of Genetics, Mishima.

PORTERES, R. 1950. Vieilles agricultures l'Afrique intertropicale. L'Agronomie Tropicale, 5, 489-507.

PRICE, S. 1957. Cytological studies in Saccharum and allied genera. III. Chromosome numbers in interspecific hybrids. Bot. Gaz., 118, 146-159.

SANO, Y. 1985. Interspecific cytoplasm substitutions of an Indica strain of Oryza sativa L. and O. glaberrima Steud. Euphytica, 34, 587-592.

SANO, Y., CHU, Y. E. AND OKA, H. I. 1980. Genetic studies of speciation in cultivated rice. 2. Character variations in backcross derivatives between Oryza sativa and $O$. glaberrima: M-V linkage and key characters. Jpn. J. Genet., 55, 19-39.

SANO, Y., SANO, R. AND MORISHIMA, H. 1984. Neighbour effects between two co-occurring rice speices, Oryza sativa and O. glaberrima. J. Appl. Ecol., 21, 245-254.

STALKER, H. T., HARLAN, J. R. AND DE WET, J. M. J. 1977. Observations on introgression of Tripsacum into maize. Amer. J. Bot., 64, 1162-1169.

STEELE, W. M. 1978. Plant exploration in Benue and Plateau States, Nigeria. Rep. Genetic Resources Unit, Intern. Inst. Trop. Agric., Ibadan.

TAKAhatA, N. AND Slatkin, M. 1984. Mitochondrial gene flow. Proc. Natl Acad. Sci. USA, 81, 1764-1767.

VIRMANI, S. S. AND ATHWAL, D. S. 1973. Genetic variability for floral characters influencing outcrossing in Oryza sativa L. Crop Sci. 13, 66-67.

WHITEHEAD, D. R. 1969. Wind pollination in the angiosperms: Evolutionary and environmental considerations. Evolution, $23,28-35$.

YABUNO, T. 1977. Genetic studies on the interspecific cytoplasm substitution lines of Japonica varieties of Oryza sativa L. and $O$. glaberrima Steud. Euphytica, 26, 451-463.

ZOHARY, D. AND FELDMAN, M. 1962. Hybridization between amphiploids and the evolution of polyploids in the wheat (Aegilops-Triticum) group. Evolution, 16, 44-61. 